\title{
Introduction to Counseling: An emerging concept in Clinical Social Work Practice
}

\author{
Dr. Syeda Farhana Sarfaraz \\ Assistant Professor and Clinical Social Worker, Department of Social Work, University of Karachi
}

\begin{abstract}
Counseling is part of every culture, either formal or informal. But new trends have emerged to transform the structure and role of family which has reduced the capacity to serve as the safety net for people who are not capable in handling the stressor for any reasons. Professional counseling is a lot of advanced social aptitudes or abilities in which focus is encourages the client's change in the therapeutic process. It depends on the client's, strength, their qualities, their convictions, their uniqueness with their entitlement to self-assurance. The counseling in social work requires intense training and develop understanding regarding human nature, behavior, and explicit therapeutic potential, ethical and healthy professional boundaries. This type of training incorporates mindfulness, evaluation of social and cultural impacts, advancement, abilities, religion, social character, gender role, socio-economic status, and nationality. Counselors basically value such differences and stay away from discrimination. It includes interacting and intervening with current issues, addresses crises situations, either short term or long-term solutions, depends on the nature of crises. It very well may work with individual, couples, families or groups. Counselors utilize the enhanced capacity and the self effectively in therapeutic environment. In this article, researcher trying to explore counseling i) the meaning and concept of counseling in social work, ii) clinical social work practices , iii) assessment tools, iv) counseling skills, v) related theories, vi) utility of counseling and emerging role and challenges of counseling in contemporary society.

Key Concept: Counseling -Clinical Social Work- Therapeutic relationship -interpersonal process of counseling-
\end{abstract} assessment tools \& skills- contemporary practices.

DOI: $10.7176 / \mathrm{JESD} / 10-12-16$

Publication date:June $30^{\text {th }} 2019$

\subsection{Introduction:}

Counseling is among the fundamental outcomes of practice in social work and mainly comprises of the main mode through which social workers directly connecting with clients; who are deprived and needs support. In-person and one to one communication between counselor and clients occur for the most part through guiding exercises. Aside from the legitimately gainful impact that happens through counseling, a great part of the approach is that can be received in explicit cases for other interventionist action is settled based on input given by counselors. This task means helps examine and analyze the importance of counseling in social work practice.

According to Professor Helen Harris, (2002) Social work uses a lot of skills, intervention methods, strategies, and programs that are adjusted to its all-encompassing focus on people and their surroundings such as, counseling/ case management/group work/psychotherapy/ and family therapy, as well as assessing people in their environment, and connect clients to available community resources. Social worker plays multiple roles provides strengthening and empowering clients/ provides support and all services structure based on client's strength, need and requirements.

At this stage we need to understand the core values in Social Work, there are 6 basic core values in social work:

- $\quad$ services to humanity

- $\quad$ social justice

- maintain dignity and worth of the individual

- $\quad$ upholding the significance of human relationship

- Integrity 
- $\quad$ competency (Bisman 2004)

\subsection{Clinical Social Work:}

The social case work is the basic method, which believes, there are many contributing factors involved in a person's problems, primary task is to develop self-direction and independence of client. As Fried Lender explains "Social case work is a method which helps by counseling the individual client to effect better social relationships and a social adjustment that makes it possible for him to lead a satisfying and useful life."

Prof Perlman 1957, explained well that, social case work as a process used by certain human welfare agencies to help individual to cope more effectively with their problems in social functioning and the nucleus of the case work is that a person with a problem comes to a place where a professional representative helps them by a given process, thus we find above mentioned elements in the process of case work (Counseling). From a counselor perspective, 4 phases are important i) building relationship with client, ii) exploring the nature of problems, and iii) finding solution selected and accepted by the client and iv) evaluation.

The leading principle of the social work being a profession, clinical social work has following 3 objectives:

- $\quad$ analysis and treatment of bio-psycho-social inability, or incapability including mental /emotional disabilities and developmental inabilities;

- $\quad$ bio-psycho-social malfunctioning ideal counteractive plan of action; and

- $\quad$ support and improvement of biopsychosocial qualities and working capacity

(Caddigan \& Pozzuto 2010)

\subsection{Theoretical Foundation:}

There are some foundation of theoretical knowledge and practice contributing the specific field of clinical social work like;

- The human behavior and development

- Psychopathology

- Symptomatology

- Racial, ethnic, cultural socioeconomics differences

- Social issues

- Diversity related with sex, age, sexual direction and inability

- Strengths and stressors in the social environment

- $\quad$ Social framework structure and elements (Dean, 1998)

There are some practicing theories and methods are also integral part of clinical social work, which makes it reliable and professional. Different areas of body of knowledge basically derived from other allied profession like psychology/sociology/ anthropology/statistics etc. Following are the theories and practice methods;

- Theories of psychotherapy/counseling (e.g., dynamic, behavioral, cognitive, psychological, family theory

- Treatment standards, modalities, and techniques

- Interviewing strategies (e.g., client engagement, intake of history, confronting and supportive techniques 
- Principles and strategies of professional collaboration

- Advocacy techniques for clients

- $\quad$ Case management and coordinated care methods (Caddigan \& Pozzuto 2010)

\subsection{Objectives of the Study:}

The main objective of the study is that introduce counseling as profession and trying to understand the analogy of counseling its foundation and challenges in contemporary society.

\subsection{Meaning, Concept and Definition of Counseling:}

The basic role of counseling is to make changes in mind-set, dispositions, conduct, contemplations and emotions that have kept the client from getting a charge out of life and understanding his/her potential. Counseling includes sharing delicate, personal, and confidential information that may, now and again, be upsetting. Over the span of counseling, clients frequently experience times of uneasiness or disarray. Counseling is best cultivated when it is a consolidated exertion between the counselor and client. Conversing with a counselor, alone, does not ensure achievement or advancement. The dimension of fulfillment for a specific individual isn't predictable.

Counseling is fulfilling the requirements of profession, because profession is recognized by having: an assortment of information, authorize training programs, an expert association of social worker, credentialing of specialists, for example, licensure, a code of conduct, lawful acknowledgment, and different norms of magnificence. (Myers et.al,2011)

Burks \& Stefflre, 1979 in their book, explained counseling as a "professional relationship between a trained counselor and a client....It is designed to help clients to understand and clarify their views of their life space, and to learn to reach their self-determined goals through meaningful, well-informed choices and through resolution of problems of an emotional or interpersonal nature."

Counselling has also related to a portion of the basic standards of social work, especially about perceiving the natural estimation of the individual and respecting the person. (Pease \& Fook, 1999)

As counseling, in its fundamental structure, formal meeting of a counselor and a client in a private and confidential environment to explore the mental and emotional challenges, and stress, the client might have considering differing individual explicit reasons. (Rowland, 1993).

According to Feltham \& Dryden 1993, counseling is a principled relationship characterized by the at least one psychological hypothesis and a perceived communication ability, adjusted by understanding, instinct, and other relational variables, to clients' special concerns, issues or goals.

As indicated by the British Association for Counseling and Psychotherapy website 2013, Counseling and psychotherapy are umbrella terms that a range and scope of talking treatments. They are conveyed through professionals, who are trained and work with individuals over a short or long haul to enable clients to achieve compelling change or upgrade their prosperity.

As Canadian point of view counseling is individuals contact social worker when they are experiencing a troublesome period in their own, family and additionally work lives. Social workers help distinguish the reasons of stress or problem, help individuals to create adapting aptitudes and find powerful answers for their concerns. They offer different types of guiding and treatment and intervene between clashes. (OASW Association of Social Workers 2019)

American Counseling Association site 2013, Counseling is an expert relationship that engages various people, families, and groups to achieve psychological well-being, wellbeing, instruction, and profession objectives.

In the light of above definitions of the key pre-assumptions of counseling are following:

- Counseling is a movement that can possibly occur if the individual looking for help, the customer, needs it to occur. It happens when a person voluntary sharing his problems with counselor and enter to specific kind of problems, finding ways for possible solutions.

- An individual looking for problems in living and has no choices to resolve it. In this situation counselor not only working towards reduce the problems and empowering client to overcome his problems by using his own strength. 
- Fundamentally, counseling is based on talking, dialogue, and discussion and figure out new possibilities between two people.

- Counseling heavily relies on the making of a connection between two individuals, which is adequately secure to permit the individual looking for assistance to investigate issues that are agonizing and disturbing.

- A client who looking for counseling has qualities and skills, that can be utilized in the problem-solving process.

- Counselor is grounded in conventional human characteristics, for instance, good listener, empathetic behavior, personal integrity, using his resources and client's strength in resolving issues that arise in client's everyday life.

- As a client or a person seeking counseling, he welcomes and accepts another person to answer his questions, sharing his personal things with counselor, and counselor respect the difference, maintained confidentiality and positive affirmation and trust on client's strength.

- Counseling practice is based on the distinctive core value, moral values, respect of another person need and strength of a person.

- Counseling represents a bunch of support for clients, opportunity of self- reflection and restoration. The counselee and counselor make use of available resources such as discussion/thoughts/theories/assumptions/criticalthinking/underlyingissues/emotions/problem-solving strategies/talks/ technologies/maintaining objectives/to get a solution of the initial issues/ decision making engage in counseling.

- There are 3 potential results of counseling are; i) resolution of the problems means understanding/perspective/acceptance/action plan of the issue, ii)learning always starts with engagement in the process of change, new set of skills/coping strategies/confidence that apply these skills in any situation arise ahead in their life and iii)social inclusion is the ultimate goal of counseling and plays an active role in the society.

- Counseling is a part of every culture and society, a counselor and a counselee and its always designed by felt needs, cultural context and, organizational requirement of the community. It reflects the economic, cultural, social, and historical factors and consistently responsive to social change.

\subsection{Scope of Counseling:}

Counseling addresses a wide range of services for those who are in need social/mental/financial relationship/interpersonal issues/environmental and mental disorders through a professional way that includes:

-Depression

-Anxiety

- Stress Management

-Grief and Loss

-Anger issues

-Alcohol and Drug abuse

-Addictive Behaviors (food, sex, drug, alcohol, work)

-Self-Defeating Behaviors

-Child Abuse (physical, emotional, and sexual)

-Trauma/sexual abuse/ accidents

-Low Self-Esteem

-Career Transition

-Social Anxiety

-Sexual Orientation and identification / Transition

-Guilt

-Lack of Assertiveness

-Relationship Concerns and Conflict

-Effective Communication issues

-Eating disoder / Body Image Issues

-Gender Identity Concerns

-Trust / Intimacy Issues

-Separation / Divorce

-Infidelity

-Sexual behavioral (low sexual desire, sexual addictions, performance problems) 


\subsection{Counseling Assessment tools:}

The assessment is the process of collecting information in a systematic manner to evaluate the nature and density of the problem that a client brings to counseling sessions. These are the major technical tools for the assessment of clients need and understanding of client's problems.

-Initial assessment \&establishing rapport with client (intake)

-Problem identification \& exploration (case history/mental, behavioral, medical \& psychological examination) -Planning Phase (Initiate intervention)

-Appropriate solution \& termination

-Chemical dependency

-Clinical Record keeping

-Standardized assessment for systematic assessment

-Law and regulations for effective clinical practice

-Research \& Evaluation (ABECSW 2002)

\subsection{Practicing Counseling Skills:}

These are some of the vital counseling techniques and skills which every counselor likely to use in their clinical practices:

- $\quad$ Accepting clients: It means accept client who they are with unconditional positive respect to them.

- Observation: It includes eye contact/body language/ clients' responses/ facial expression are the main non-verbal communication.

- Active Listening: It is most important counseling skills in maintaining relationship. It means giving undiligent attention, noncritical acceptance, encouraging to speak more or paraphrasing.

- Asking Questions: There are two type of questions open and close ended ones asked to the enhance the therapeutic relationship between client and social worker's deeper insight of the problem.

- Positive Affirmations; It is to support/ encourage client to use his /her strength towards achieving goals of counseling.

- Empathy: It is basic the ability of a counselor to put him/herself in client's shoes to understand clients feeling/pain/limitation and experiences.

- Goal setting: Basically, maintaining goals initially, will help client and counselor to focused on problem solving and selection of intervention and techniques.

- Non-Judgmental Behavior: It is the basic requirement of counseling process to avoid judging and moralistic responses of the client with the understanding of boundary awareness. (Egan 1990; Jacobs 1982; McLeod 1998; Nelson-Jones 1981).

Counseling helps to understand the different learning styles and diverse needs of the clients. Effective counseling is should be creative and responsive in nature, addresses the unique needs of the client with the understanding of cultural competency. Following are the positive outcomes of counseling:

- It gives the insight about the cause and effects of emotional and learning abilities/limitation as well as an increase positive self-control.

- It improves overall relationship with other people such as personal or professional.

- It gives a chance to be self-aware of thoughts/feeling/hindrances in the situation which creates blockage.

- It gives a self-acceptance and acknowledgement of own thoughts/feeling/experiences/self- criticism.

- It gives a self-actualization, how to move on in the situation according to the goals and achieving a combination of conflicting parts of self.

- It provides insight and spiritual awakening of self and environment.

- It provides to practice problem solving approach towards problems in life.

- It enables the client to learn new ideas/skills/strategies to understand and control their own behavior.

- It enhances the scope of learning in terms of social/interpersonal skills/assertiveness/anger control/maintaining healthy boundaries.

- It modifies the irrational concepts/maladaptive practices through social experiences.

- It modifies the maladaptive patterns of behavior. 
- It acquaints social change with clients into the route in that social frameworks working environment/families/society they work.

- It provides awareness/knowledge/skills that will support to client to manage his or her own life.

- It helps to restitutes the client to improve destructive behavior

\subsection{Practicing Supportive Counseling theories:}

\section{Psychoanalytic Theory:}

Sigmund Freud was presented this theory, about the oblivious powers that drive human activities. A psychoanalytic counseling incorporates aptitudes, for example, dream examination, free affiliation, opposition examination, and transference examination identified with adolescence and similarities are recognized and investigated in the remedial union among the counselor and the client.

\section{Person-Centered Therapy:}

Carl Roger's presented this theory about that every person can use their full potential.it is a client-centered approach that includes, self-actualization, empathy, and unconditional positive regard. In this connection, helpful connection among client and counselor is vital with the understanding of the idea that client is the expert in their own life. The positive interactions are the end results of therapy.

\section{Cognitive Behavioral Therapy (CBT):}

It is a shorter-term and hands-on method about the theory that human problems stem from negative thinking patterns. This process includes the test of programmed thinking and frequently negative idea designs. It motivates the client to figure out logic and counselor plays an supportive role in challenging the negative thinking pattern.

\section{The Family Systems Model:}

Murray Bowen was presented this theory, that all human problems and issues as a familial unit. Family is the essential reasons of feelings and can be available in numerous structures, including auxiliary, vital, and intergenerational. The making of a genogram, family projection exercises, passionate triangles, and the separation of self are the principle strategies and normally utilized in marriage and family counseling.

We can say that counseling is making strong therapeutic relationship with clients that enable them to acquire social/mental health and to achieve their objectives in life. There are many titles that refer to professional counselors who are practicing counseling, and work with specific clientele, such as mental health counselor, addiction counselor/marriage/couple counselor grief counselor or student counselor. These counselors have specialist training/expertise in there are of specification along with regular counseling training. Now a days these counseling practices provides such as individual / with groups/ couples/ with families with different mode of counseling are available i.e., telephonic counseling and internet, what's more, through-composed materials, for example, books and self-improvement manuals.

Typically, fundamental locations of counseling are medical organizations and they refers clients according to their situation to the psychiatric services, clinical social work counseling services and other community resources.

Counselors ethically and professionally bound to renew their licenses yearly, enhance their knowledge, skills and improve their professional development throughout their career such as clinical supervision, consultation, and selfstudy to maintain practice standards with clients.

\subsection{Challenges for Counseling in contemporary situation:}

In contemporary society, conflict is everywhere in the society, a series of challenges like trauma, violence, wars, terrorist attacks, national disaster, drugs and alcohol addiction, media addiction, are common experiences for everyone. On the other hand, dealing with trauma, depression. Stress, PTSD, anxiety, disabilities, economical stress, transition, weakened family system, and youth issues, increases day by day.

Expensive health care and managed care is also a big issue for counselors. Few companies offers managed health care, and they need to see the doctors, first and referrals required for further process of counseling, then limited number of session, entitlement of counseling services, are the another kind of issues counselors are facing. 
There are some moral concerns in health services from counselors to clients are around issues like informed assent, privacy, looking after records, fitness, honesty, human welfare, irreconcilable circumstance, and states of work (Daniels, 2001)

\subsection{Conclusion:}

In this article, researcher tried to provide the meaning and concept of counseling with current practices and perspectives of client and counselor.it is a safe space of talking with specific goal and time frame but flexible process of helping clients, enables them to explore problem solving strategies, with due respect of diversity and cultural competency. It understands the client's perspectives of the problems and giving them a chance to improve their situation by utilizing their own strength. Now facts and figures show that professional counseling community is growing and is accessible in a wide scope of community settings around the globe.

\section{Bibliography}

1. ABECSW 2002, Professional Development and Practice Competencies in Clinical Social Work A Position Statement of the American Board of Examiners in Clinical Social Work, published March, 2002, http://acswa.org/wp-content/uploads/Competen.pdf accessed on March 2017

2. Bisman, C. (2004). Social Work Values: The Moral Core of the Profession. The British Journal of Social Work, 34(1), 109-123. Retrieved from http://www.jstor.org/stable/23719986

3. Bond, T, 2000, Standards and Ethics for Counselling in Action, Sage Publications Ltd. London

4. Burks,H.M. and Stefflre, B” Theories of Counseling, 9780070090613 https://books.google.ca/books?id=M76cAAAAMAAJ, 1979 McGraw-Hill https://www.mheducation.co.uk/openup/chapters/0335211895.pdf

5. Corney, R. \& Jenkins, R, (Eds.), 1993, Counselling in General Practice. London: Routledge

6. Counselling saves British business millions every year, 2003, British Association for Counselling and Therapy, Retrieved December 3, 2018 from www.instituteofwelfare.co.uk/downloads/welfare_world_24_full.pdf

7. Dryden, W, 2006, Counselling in a nutshell, Sage Publications Ltd. London

8. Dryden, W., \& Mytton, J, 1999, Four Approaches to Counselling and Psychotherapy, London: Routledge

9. Dean, H. E. (1988, November). The primacy of the ethical aim in clinical social work: Its relationship to social justice and mental health. Smith College Studies in Social Work, 69(1) 9- 24.

10. D'Andrea, M., \& Daniels, J. (2001). RESPECTFUL Counseling: An Integrative Model for Counselors. In D. Pope-Davis, \& H. Coleman (Eds.), The Interface of Class, Culture and Gender in Counseling (pp. 417-466). Thousand Oaks, CA: Sage.

11. Dryden, W, 2006, Counselling in a nutshell, Sage Publications Ltd. London

12. Dryden, W., \& Mytton, J, 1999, Four Approaches to Counselling and Psychotherapy, London: Routledge

13. Feltham, C, 1995, What Is Counselling? The Promise and Problem of the Talking Therapies, Sage Publications Ltd. London

14. Friedlander, W.A. \&Blumer, H.' Concepts and Methods of Social Work" https://books.google.ca/books?id=TQeTuAAACAAJ 2012 Literary Licensing, LLC

15. H H Perlman,1957, Social Casework: A Problem-Solving Processes 9780226660332 https://books.google.ca/books?id=4MHzrn1Jy-AC University of Chicago Press

16. Harrow, J, 2001, Working Models: theories of counselling, Retrieved December 3, 2018 from http://www.draknet.com/proteus/models.htm

17. Harris, J, 2002, The Social Work Business /. London: Routledge

18. Margaret Arnd-Caddigan \& Richard Pozzuto (2010) Evidence-Based Practice and the Purpose of Clinical Social Work, Smith College Studies in Social Work, 80:1, 3552, DOI: 10.1080/00377310903504965

19. Meyer, G. J., Finn, S. E., Eyde, L. D., Kay, G. G., Moreland, K. L., Dies, R. R., . . Reed, G. M. (2001). Psychological testing and psychological assessment: A review of evidence and issues. American Psychologist, 56(2), 128-165. http://dx.doi.org/10.1037/0003-066X.56.2.128

20. OASW, Ontario Association of Social Worker https://www.casw-acts.ca/en/111-frequently-askedquestions accessed Dec 32018 
21. Miller, L, 2005, Counselling Skills for Social Work, Sage Publications Ltd. London

22. Moore, P, 2003, Critical components of an anti-oppressive framework, The International Child and Youth Care Framework, Retrieved December 3, 2007 from www.cyc-net.org/cyc-online/cycol-1203moore.html

23. Nelson-Jones, R, 2000, Six key approaches to counselling and therapy, Sage Publications Ltd. London

24. Noonan, E, 1983, Counselling Young People. London: Tavistock Routledge

25. Pease, B. \& Fook, J. (Eds.), 1999, Transforming Social Work Practice: Postmodern Critical Perspectives. London: Routledge

26. Retail Therapy: Beauty So Tell Me, What's the Problem? Laura Davis Investigates the Growing Trend for Counselling, 2004, October 28, Daily Post (Liverpool, England), p. 8

27. Rowland, N, 1993, Chapter 3 What is Counselling? In Counselling in General Practice, Corney, R. \& Jenkins, R. (Eds.) (pp. 17-30) London: Routledge

28. Shardlow, S. (Ed.), 1989, The Values of Change in Social Work. London: Tavistock/Routledge

29. Starkey, P, 2000, Families and Social Workers : The Work of Family Service Units, 1940-1985 /. Liverpool, England: Liverpool University Press

30. Thompson, N (2001) Anti-Discriminatory Practice, Third Edition, London: Palgrave

31. Urofsky, R. I., \& Engels, D. W, 2003, Philosophy, Moral Philosophy, and Counselling Ethics: Not an Abstraction. Counselling and Values, 47(2), 118+ 